\title{
Respostas de genótipos de palma forrageira a diferentes densidades de cultivo ${ }^{1}$
}

\author{
Lucas Aroaldo Dantas Cavalcante ${ }^{2}$, Gladston Rafael de Arruda Santos ${ }^{2}$, \\ Laerte Marques da Silva², Jailson Lara Fagundes², Mônica Alixandrina da Silva ${ }^{3}$
}

\begin{abstract}
Response of cactus pear genotypes to different crop densities

Considering the importance of cactus pear as an alimentary alternative for the herd of cattle of the Brazilian semiarid region and the effect of crop spacing among plants, this study aimed to evaluate the morphometry, yield and chemical-bromatological composition of cactus pear genotypes, under different cropping densities. The experimental design was completely randomized blocks, in a $3 \times 4$ factorial scheme. Treatments consisted of a combination of three cactus pear genotypes (Gigante, Redonda and Miúda) and four cropping densities $\left(10,000\right.$ plants ha ${ }^{-1}$; 20,000 plants ha ${ }^{-1} ; 40,000$ plants ha $^{-1}$; and 80,000 plants ha $\left.{ }^{-1}\right)$, with three replications. The cactus pear genotypes reacted differently, regarding morphometry, yield and chemical-bromatological composition, and, regardless of the species, the denser planting increased yield (tons ha-1). The Miúda palm presented the highest dry matter yield and consequently the greater accumulation of total digestible nutrients, raw protein and water per hectare, as well as the highest in vitro dry matter digestibility.
\end{abstract}

KEY-WORDS: Opuntia sp.; Nopalea sp.; Cactaceae; bromatology.

\section{INTRODUÇÃO}

A palma forrageira tem contribuído para o desenvolvimento socioeconômico do semiárido brasileiro, por ser cultura forrageira adaptada às condições climáticas da região. O semiárido brasileiro apresenta temperaturas médias elevadas e precipitações médias anuais de 300-700 mm, extremamente concentradas. Nesse cenário, a produção de palma forrageira é uma das estratégias de apoio à convivência da pecuária regional com a seca (Silva et al. 2012).

Enquanto o crescimento de outras plantas forrageiras é limitado pelo baixo índice pluviométrico,

\section{RESUMO}

Considerando-se a importância da palma forrageira como alternativa alimentícia para os rebanhos do semiárido brasileiro e o efeito do espaçamento de cultivo entre plantas, este estudo objetivou avaliar a morfometria, produtividade e composição químico-bromatológica de genótipos de palma forrageira, em diferentes densidades de cultivo. O delineamento experimental utilizado foi em blocos completos casualizados, em esquema fatorial $3 \times 4$. Os tratamentos constituíram-se da combinação de três genótipos de palma forrageira (Gigante, Redonda e Miúda) e quatro densidades de cultivo (10.000 plantas ha-1, 20.000 plantas ha $^{-1}, 40.000$ plantas ha $^{-1}$ e 80.000 plantas ha $^{-1}$, , com três repetições. Os genótipos de palma forrageira apresentaram comportamentos diferentes, quanto à morfometria, produtividade e composição químico-bromatológica, e, independentemente da espécie, o plantio adensado elevou a produtividade (toneladas $\mathrm{ha}^{-1}$ ). A palma Miúda apresentou maior produtividade de matéria seca e, consequentemente, maior acúmulo de nutrientes digestíveis totais, proteína bruta e água por hectare, bem como maior digestibilidade in vitro da matéria seca.

PALAVRAS-CHAVE: Opuntia sp.; Nopalea sp.; cactáceas; bromatologia.

a palma suporta grande período de estiagem, por sua fisiologia especial quanto à absorção, aproveitamento e perda de água (Romo et al. 2006, Cavalcante \& Resende 2007). A eficiência no uso da água de até 11 vezes a observada nas plantas de mecanismo $\mathrm{C} 3$ torna a palma, dentre as forrageiras cultivadas, uma das espécies adaptadas ao semiárido (Alves et al. 2007).

No Brasil, estima-se que há, atualmente, aproximadamente 600.000 ha cultivados com cultivares de palma, mas, apesar dos recentes esforços governamentais para diversificar o uso da cultura, a maioria das áreas plantadas ainda é dedicada à produção de forragem (Dubeux Júnior et al. 2013).

1. Trabalho recebido em set./2013 e aceito para publicação em set./2014 ( $\mathrm{n}^{\circ}$ registro: PAT 26524).

2. Universidade Federal de Sergipe (UFS), Departamento de Engenharia Agronômica, São Cristóvão, SE, Brasil. E-mails: lucas.aroaldo@gmail.com,gladstonrafael@yahoo.com.br, ratinhojlf@yahoo.com.br, laertemarquesilva@hotmail.com. 3. Instituto Federal de Educação, Ciência e Tecnologia de Sergipe (IFS), Campus São Cristovão, São Cristovão, SE, Brasil. 
A palma forrageira é considerada fonte energética de grande potencialidade para a nutrição de ruminantes, principalmente no Nordeste Brasileiro (Tosto et al. 2007), e os genótipos mais utilizados são o Gigante (Opuntia ficus-indica L. Mill), Redonda (Opuntia sp.) e Miúda (Nopalea cochenillifera Salm-Dyck). Entretanto, o Gigante é o mais cultivado, seguido pelo Redonda e Miúda, respectivamente (Chiacchio et al. 2006).

A palma Miúda produz, em média, $68 \mathrm{tha}^{-1}$ $\mathrm{ano}^{-1}$ de massa verde (MV), em densidade de cultivo de 20.000 plantas ha $^{-1}$, com multiplicação mais rápida e maior valor nutritivo que o dos demais genótipos (Vasconcelos et al. 2007), por apresentar maiores teores de matéria seca (MS), cálcio (Santos et al. 1990) e carboidratos (Santos et al. 1992). Torres et al. (2009) relataram teores de $\mathrm{MS}=10,28 \%$; matéria orgânica $(\mathrm{MO})=87,38 \%$; proteína bruta $(\mathrm{PB})=5,48 \%$; extrato etéreo $(\mathrm{EE})=2,22 \%$; fibra em detergente neutro $(\mathrm{FDN})=12,62 \%$; fibra em detergente ácido $(\mathrm{FDA})=$ $37,32 \%$; carboidratos totais $(\mathrm{CHOT})=79,68 \%$; e carboidratos não-fibrosos $(\mathrm{CNF})=79,68 \%$. Já o genótipo Gigante atingiu 56,5 $\mathrm{t} \mathrm{ha}^{-1} \mathrm{ano}^{-1}$ de $\mathrm{MV}$, em espaçamento de $3,0 \mathrm{~m} \times 1,0 \mathrm{~m} \times 0,5 \mathrm{~m}$, em um intervalo de 4 anos entre os cortes (Farias et al. 2000), e apresentou teores de $\mathrm{MS}=10,7 \%$; $\mathrm{MO}=85,8 \%$; matéria mineral $(\mathrm{MM})=14,2 \% ; \mathrm{PB}=5,09 \% ; \mathrm{EE}=$ $2,0 \%$; $\mathrm{CHT}=78,6 \% ; \mathrm{CNF}=53,2 \% ; \mathrm{FDN}=25,4 \%$; $\mathrm{FDA}=22,0 \%$; nitrogênio não proteico $(\mathrm{NNP})=$ $37,6 \% ; \mathrm{Ca}=2,87 \%$; e $\mathrm{P}=0,36 \%$ (Melo et al. 2003). O Redonda atingiu $175 \mathrm{t} \mathrm{ha}^{-1} \mathrm{ano}^{-1} \mathrm{de} \mathrm{MV}$, em densidade de plantio de 20.000 plantas ha $^{-1}$ (Farias et al. 2000), e teores médios de $\mathrm{MS}=15,9 \% ; \mathrm{PB}=3,7 \%$; fibra bruta $(\mathrm{FB})=13,6 \%$; e CHOT $=29,1 \%$ (Santos et al. 1992).

O espaçamento de plantio na cultura da palma forrageira pode afetar a interceptação da luz e a eficiência fotossintética, influenciando no desenvolvimento e na produtividade da cultura. Plantios menos adensados facilitam os tratos culturais e reduzem os riscos de pragas, como a cochonilha do carmim, espécie do gênero Dactylopius (Oliveira Júnior et al. 2009).

Ramos et al. (2011) verificaram que a produção foi incrementada com o adensamento, porém, a composição químico-bromatológica não teve influência significativa dos espaçamentos. Espinoza et al. (2008) concluíram que o plantio adensado aumentou a produtividade de MV e MS de cinco cultivares de O. ficus-indica, havendo, consequentemente, maior disponibilidade de nutrientes por área de palmal.
O plantio adensado e associado à adubação, considerando-se que a estrutura fundiária do Nordeste é formada, na sua maioria, por pequenas propriedades, são estratégias de manejo fundamentais para aumentar a eficiência de produção de forragem (Dubeux Júnior et al. 2010). Diante do exposto, este estudo objetivou avaliar a morfometria, produtividade e composição químico-bromatológica de genótipos de palma forrageira, em diferentes densidades de cultivo.

\section{MATERIAL E MÉTODOS}

O experimento foi conduzido no Campo Experimental do Centro de Pesquisa Agropecuária dos Tabuleiros Costeiros da Embrapa (10 $32^{\circ}$ '58' S, $37^{\circ} 32^{\prime} 04^{\prime}$ 'W e altitude de $272 \mathrm{~m}$ ), em Frei Paulo (SE), de outubro de 2009 a outubro de 2011, sendo a precipitação média anual de $700 \mathrm{~mm}$ e a média pluviométrica acumulada/ano do período avaliado de $728 \mathrm{~mm}$ (Figura 1).

Amostras de solo foram coletadas e encaminhadas ao laboratório do Instituto Tecnológico e de Pesquisa do Estado de Sergipe, para realização das análises físicas e químicas (Tabela 1). O delineamento experimental utilizado foi em blocos completos casualizados, em esquema fatorial $3 \times 4$. Os tratamentos constituíram-se da combinação de três genótipos de palma forrageira (Gigante, Redonda e Miúda) e quatro densidades de cultivo (10.000 plantas ha ${ }^{-1}, 20.000$ plantas ha ${ }^{-1}$, 40.000 plantas ha $^{-1}$ e 80.000 plantas ha $^{-1}$ ), totalizando 12 tratamentos, com três repetições.

$\mathrm{O}$ espaçamento entre as linhas de plantio foi de 2,0 $\mathrm{m}$ dentro dos tratamentos, diferindo apenas o espaçamento entre as plantas. Cada densidade de plantio teve três linhas de plantas com 5,0 m de comprimento, totalizando área experimental de $30 \mathrm{~m}^{2}$, sendo considerada como área útil a linha central, desprezando-se $0,5 \mathrm{~m}$ nas extremidades da mesma. Nas densidades de 10.000 plantas ha $^{-1}, 20.000$ plantas ha-1, $^{-1}$, 40.000 plantas ha $^{-1}$ e 80.000 plantas ha ${ }^{-1}$, os espaçamentos entre as plantas, na linha de plantio, foram, respectivamente, de $50 \mathrm{~cm}, 25 \mathrm{~cm}, 12,5 \mathrm{~cm}$ e $6,25 \mathrm{~cm}$.

A área experimental foi preparada em setembro de 2009, aos 30 dias de antecedência ao plantio, com aração seguida de duas gradagens. Posteriormente, foram abertos sulcos com $30 \mathrm{~cm}$ de largura por $30 \mathrm{~cm}$ de profundidade.

O material vegetal utilizado para o plantio foi coletado em área com cultivo de palma convencional. 


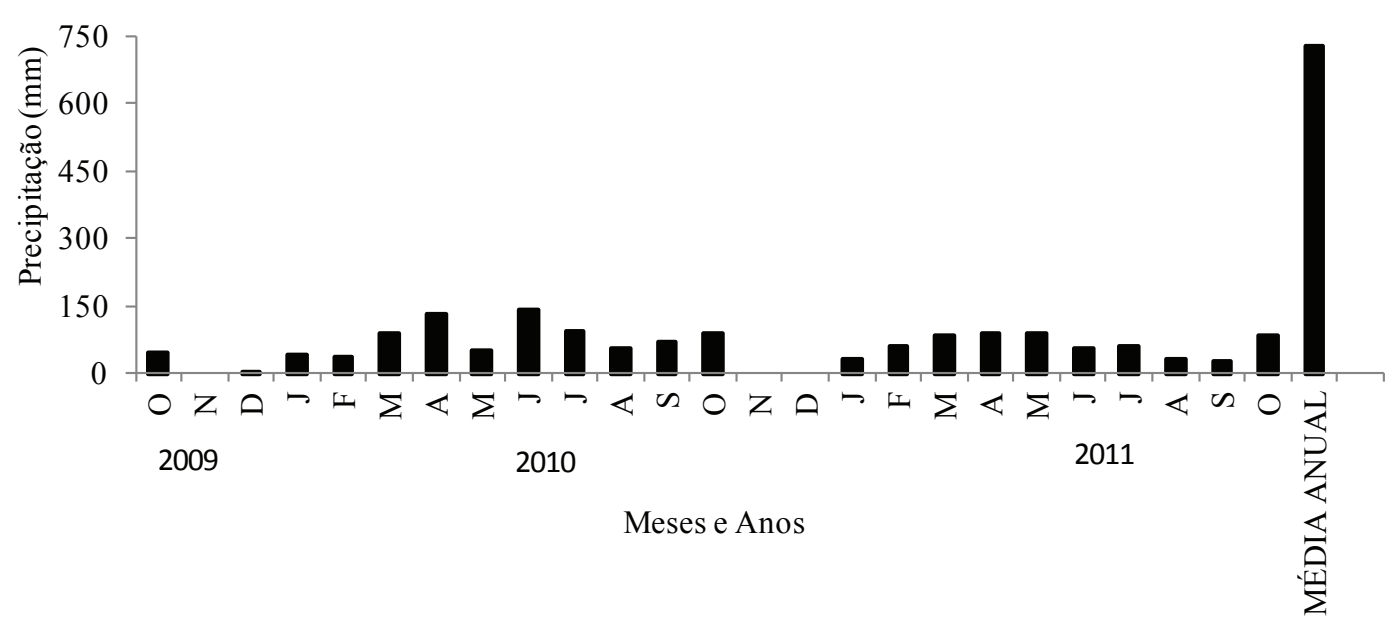

Figura 1. Precipitação mensal e média acumulada/ano, durante o experimento. Fonte: Dados fornecidos pela Embrapa Tabuleiros Costeiros, em 2012.

Tabela 1. Resultados da análise física e química do solo utilizado no experimento (Frei Paulo SE, 2009).

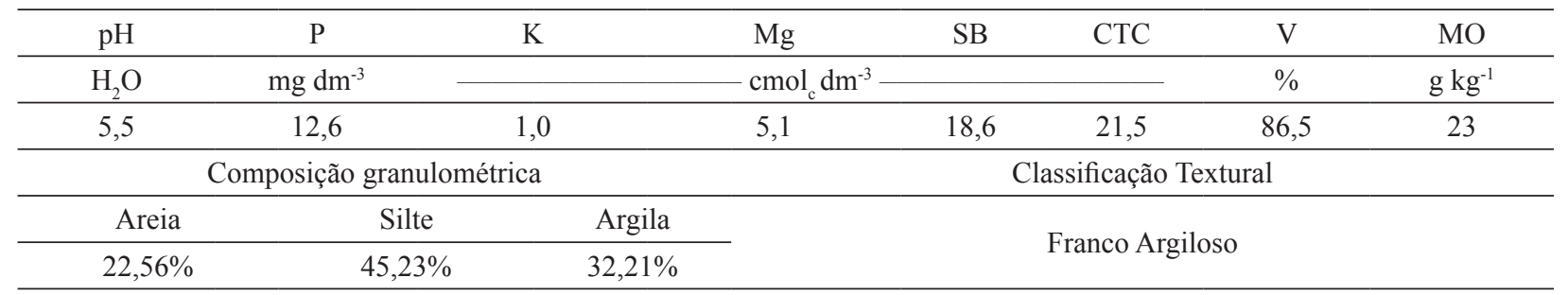

Foram utilizados cladódios intermediários (nem da base, nem dos extremos da planta), grandes, viçosos e livres de manchas e da presença de sinais de pragas ou doenças. Os cladódios com dois a três anos de idade, segundo Farias et al. (2005), são os mais recomendados, por emitirem brotações mais vigorosas.

Após o corte, no campo, o material foi colocado em repouso, à sombra, por um período de quinze dias, para cicatrização. Esse processo de cura ocorreu para impedir a entrada de micro-organismos, evitando, por conseguinte, o apodrecimento das raquetes inertes, pelo contato direto com a água, fenômeno comum no período chuvoso.

A adubação foi aplicada aos sulcos com 30 dias de antecedência ao plantio, constituindo-se de $10 \mathrm{t} \mathrm{ha}^{-1}$ de esterco de ovinos e $250 \mathrm{~kg} \mathrm{ha}^{-1}$ da fórmula 8-28-16, na forma de ureia, superfosfato triplo e cloreto de potássio, respectivamente (Sobral et al. 2007), após a coleta e análise de solo (Tabela 1).

O plantio foi efetuado com os cladódios posicionados um atrás do outro, dentro dos sulcos, enterrados dois terços na base, para garantir a firmeza, na posição vertical, com as faces no sentido leste/oeste, espaçados de acordo com os tratamentos testados. Seis meses após o plantio, foi realizada adubação de cobertura com ureia (100 kg de $\left.\mathrm{N} \mathrm{ha}^{-1}\right)$.

Aos 24 meses após o plantio, foi mensurada a altura das plantas, com o uso de fita métrica, considerando-se a distância entre o solo e o ápice da planta, e realizada a contagem do número de cladódios. Foi efetuado o corte de três plantas de palma, na área útil experimental, sendo coletados todos os cladódios (artículos), mantendo-se apenas o artículo basal. Essas plantas foram pesadas individualmente, para determinação da produção de massa verde por planta, e, em seguida, encaminhadas ao laboratório. Para as medições de largura e comprimento dos artículos, foi utilizada fita métrica, considerando-se a região de maior largura (parte central) e comprimento do artículo (distância entre inserções ou extremidades). Para avaliar a espessura do cladódio, foi utilizado paquímetro, considerando-se a mesma região onde foi realizada a medida da largura.

O peso médio dos cladódios foi calculado pela divisão da produção por planta pelo número de cladódios por planta. Foram retiradas subamostras 
dos cladódios de cada tratamento, sendo essas identificadas, pesadas e pré-secas em estufa de ventilação forçada a $55^{\circ} \mathrm{C}$, por 72 horas.

Após pré-secagem, as amostras foram moídas em moinho de faca a $1 \mathrm{~mm}$ e devidamente acondicionadas em potes plásticos, para posterior análise de composição química. No Laboratório de Nutrição Animal do Departamento de Zootecnia da UFS, foram analisados os teores de matéria seca (MS), proteína bruta (PB), matéria orgânica (MO) e matéria mineral (MM), de acordo com metodologia descrita por Silva \& Queiroz (2002); fibra em detergente neutro (FDN), fibra em detergente ácido (FDA), hemicelulose (HEM), celulose (CEL) e lignina (LIG), segundo o método de Van Soest et al. (1991); e proteína insolúvel em detergente neutro (PIDN) e proteína insolúvel em detergente ácido (PIDA), segundo metodologia descrita por Licitra et al. (1996).

Para a estimativa dos carboidratos totais (CHOT), foi utilizada a equação proposta por Sniffen et al. (1992): $\mathrm{CHOT}=100-(\% \mathrm{~PB}+\% \mathrm{EE}+\% \mathrm{MM})$, e, para a estimativa dos carboidratos-não-fibrosos (CNF), a equação preconizada por Hall (2003): $\mathrm{CNF}=\% \mathrm{CHOT}-\% \mathrm{FDNCcp}$, adaptada com base em Detemann \& Valadares Filho (2010), onde a FDN foi corrigida para cinza e proteína (FDNcp). O nutriente digestível total foi estimado pela equação NDT $(\%)=$ $\mathrm{PBD}+$ 2,25 EED + CNFD + FDND - 7 (USA 2001) e pela equação NDT $=83,79$ - 0,4171 FDN (Capelle et al. 2001). Para o ensaio de digestibilidade da MS, foi utilizada a técnica in vitro em fermentador ruminal (Tilley \& Terry 1963). O acúmulo, por área, de água ( $\mathrm{tH}_{2} \mathrm{O} \mathrm{ha}^{-1 / 2}$ anos), $\mathrm{PB}$ (tPB ha ${ }^{-1 / 2}$ anos) e NDT (tNDT ha ${ }^{-1} / 2$ anos) foi calculado pela multiplicação da produção de MS pelo teor do nutriente.
Os dados foram analisados segundo o procedimento GLM do pacote estatístico Statistical Analysis System (SAS 2002). Após análise de variância, os tratamentos quantitativos em que não foi verificada interação foram submetidos à análise de regressão e os tratamentos qualitativos, por sua vez, ao teste Tukey, a 5\%. Quando constatada interação entre as variáveis qualitativas e quantitativas, foi realizado desdobramento da interação, dentro de cada tratamento qualitativo analisado com regressão.

\section{RESULTADOS E DISCUSSÃO}

A palma Miúda apresentou maior número de cladódios por planta (NCP) e os menores valores de comprimento e largura dos cladódios. Isso porque as plantas pertencentes ao gênero Nopalea sp. apresentam maior quantidade de cladódios e cladódios menores, quando comparadas às do gênero Opuntia sp., na palma Miúda (Tabela 2).

Não houve interação entre genótipos e densidades de cultivo, para NCP, comprimento, largura e espessura de cladódio e altura de planta. Com o aumento da densidade de plantio, houve efeito quadrático negativo no número de cladódios por planta, possivelmente devido à maior competição entre as plantas por espaço, promovendo diminuição na emissão de cladódios (Figura 2).

Também houve redução quadrática no comprimento e largura de cladódios, com o aumento da densidade de plantio (Figura 2). Além de reduzir a quantidade de cladódios emitidos por planta, a elevação na densidade de plantas também proporcionou redução no tamanho dos mesmos.

A maior população de plantas pode ter elevado a competitividade das plantas por nutrientes e luz.

Tabela 2. Número médio de cladódios por planta (NCP), comprimento, largura, espessura de cladódio e altura de planta da palma forrageira cultivada em diferentes densidades de cultivo (Frei Paulo, SE, 2011).

\begin{tabular}{|c|c|c|c|c|c|}
\hline \multirow{2}{*}{ Tratamento } & \multirow{2}{*}{$\mathrm{NCP}$} & Comprimento & Largura & Espessura & \multirow{2}{*}{$\begin{array}{c}\text { Altura } \\
\mathrm{m}\end{array}$} \\
\hline & & & $\mathrm{cm}-$ & & \\
\hline Gigante & $17,00 \mathrm{~b}$ & $31,20 \mathrm{a}$ & $15,96 \mathrm{~b}$ & $2,92 \mathrm{a}$ & $1,27 \mathrm{a}$ \\
\hline Redonda & $15,92 \mathrm{~b}$ & $25,68 \mathrm{~b}$ & $18,55 \mathrm{a}$ & $2,46 \mathrm{~b}$ & $0,97 \mathrm{~b}$ \\
\hline \multirow[t]{2}{*}{ Miúda } & $81,50 \mathrm{a}$ & $22,02 \mathrm{c}$ & $9,55 \mathrm{c}$ & $2,32 \mathrm{~b}$ & $1,10 \mathrm{~b}$ \\
\hline & & & or de F & & \\
\hline Genótipo (G) & $39,37 * *$ & $76,45 * *$ & $173,61 * *$ & $27,19 * *$ & $10,98 * *$ \\
\hline Densidade (D) & $5,22 * *$ & $4,32 *$ & $3,84 *$ & $2,37^{\mathrm{ns}}$ & $1,37^{\mathrm{ns}}$ \\
\hline $\mathrm{G} \times \mathrm{D}$ & $2,23^{\mathrm{ns}}$ & $0,93^{\mathrm{ns}}$ & $0,98^{\mathrm{ns}}$ & $4,41^{\mathrm{ns}}$ & $0,37^{\mathrm{ns}}$ \\
\hline CV (\%) & 54,36 & 6,96 & 8,29 & 8,18 & 14,03 \\
\hline
\end{tabular}


Dubeux Júnior et al. (2006) concluíram que o NC foi superior na menor densidade de plantas, devido à maior superfície de solo explorada. Por outro lado, a maior população tinha oito vezes mais plantas por unidade de área. Sendo assim, o NC por área foi maior nas parcelas com maior população de plantas. Segundo Nascimento et al. (2011), o crescimento da palma forrageira é influenciado pela densidade de plantio, tendendo à redução de número, tamanho, forma e peso dos cladódios, com o aumento da densidade populacional.

$\mathrm{O}$ adensamento fez com que a planta emitisse maior número de novos brotos, uma vez que não havia espaço para que esses crescessem. Possivelmente, os cladódios não conseguiram se desenvolver devido à sobreposição dos mesmos. Por isso, o número e tamanho de cladódios por planta diminuíram.
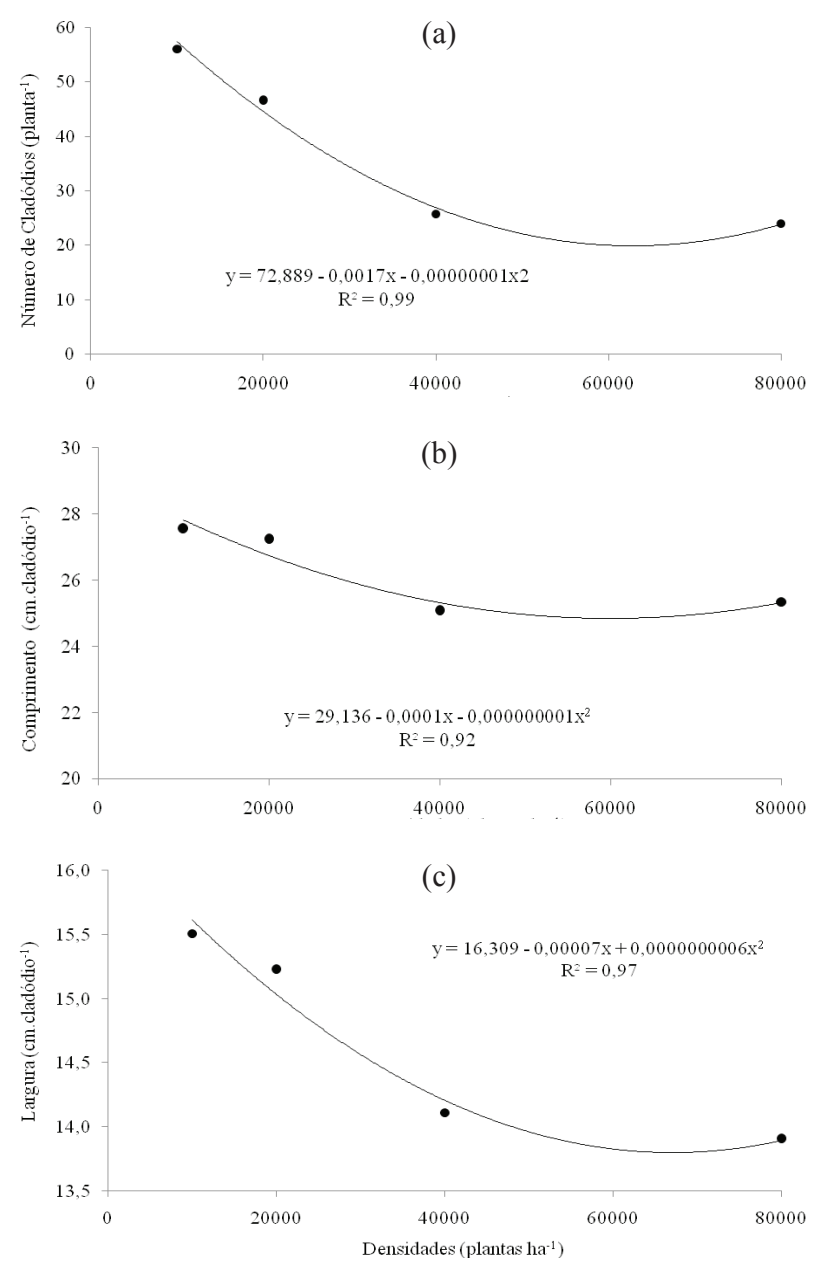

Figura 2. Número médio de cladódios por planta (a), comprimento (b) e largura média (c) de cladódios de palma forrageira, em função da densidade de cultivo (Frei Paulo, SE, 2011).
Não houve interação entre genótipos e densidades de cultivo, para produtividade e peso de cladódio. Devido ao menor número de cladódios por planta, as palmas Gigante e Redonda apresentaram cladódios mais pesados, quando comparadas com a palma Miúda. Essa, por sua vez, apresentou cladódios mais leves, porque a planta necessita distribuir os nutrientes para uma grande quantidade de cladódios (Cunha et al. 2012).

A palma Miúda, embora tenha cladódios menores e mais leves, se comparados aos da Gigante e Redonda, possui maior teor de MS (Tabela 4) e maior $\mathrm{NCP}$, em relação à Gigante e à Redonda, e, consequentemente, maior produtividade de MS (Tabela 3).

A resposta quadrática positiva para produtividade de massa verde e seca da palma forrageira, nas maiores densidades de plantio (Figuras 3a e 3b), está diretamente relacionada ao aumento do número de plantas por hectare, uma vez que os números de cladódios por planta e o tamanho desses cladódios diminuíram com o aumento das densidades. $\mathrm{O}$ aumento da produtividade ( $\mathrm{t}$ de $\mathrm{MS} \mathrm{ha}^{-1 / 2}$ anos) nas maiores densidades de plantio está diretamente relacionado ao maior número de plantas, que, mesmo com menos cladódios e cladódios menos pesados, proporcionou maior produtividade.
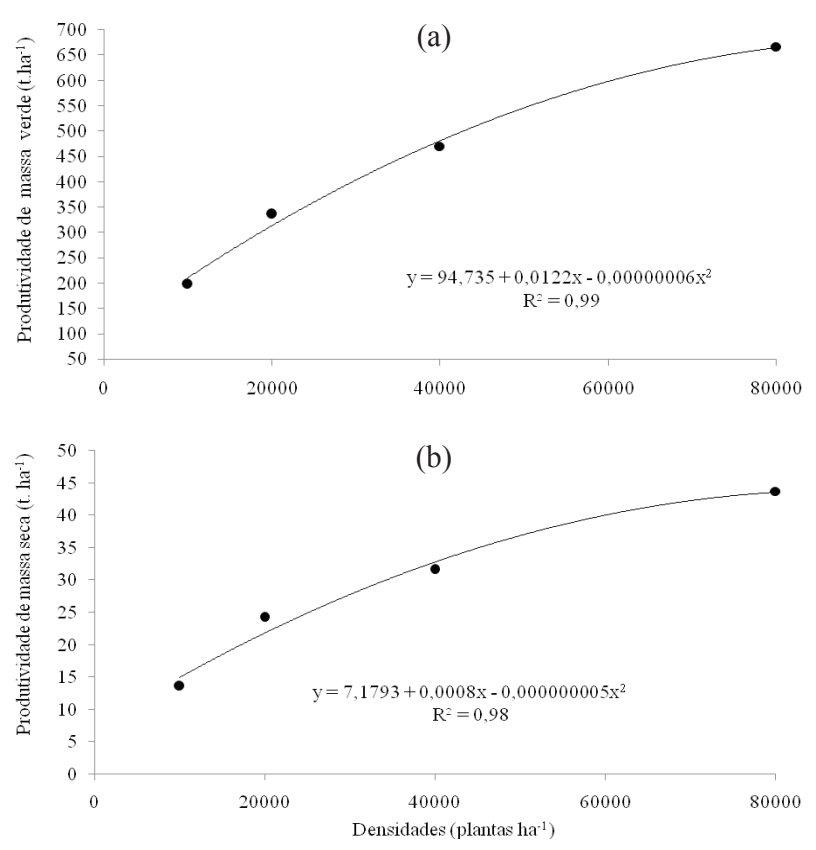

Figura 3. Produtividade em matéria fresca (a) e seca (b) de palma forrageira das cultivares Gigante, Redonda e Miúda, em função da densidade de plantio (Frei Paulo, SE, 2011). 
Tabela 3. Massa média fresca e seca por cladódio e produtividade, a cada dois anos, em matéria fresca e matéria seca da palma forrageira, em função da densidade de plantio (Frei Paulo, SE, 2011).

\begin{tabular}{|c|c|c|c|c|}
\hline \multirow{3}{*}{ Tratamento } & \multicolumn{2}{|c|}{ Massa média cladódio $^{-1}$} & \multicolumn{2}{|c|}{ Produtividade } \\
\hline & Matéria fresca & Matéria seca & Matéria fresca & Matéria seca \\
\hline & $\mathrm{g}$ & $\mathrm{t} \mathrm{ha}^{-1}$ & $\mathrm{~g}$ & $\mathrm{t} \mathrm{ha}^{-1}$ \\
\hline Gigante & $731,74 \mathrm{a}$ & $46,12 \mathrm{a}$ & 379,83 & $24,07 \mathrm{~b}$ \\
\hline Redonda & 829,08 a & $50,31 \mathrm{a}$ & 392,83 & $23,32 b$ \\
\hline Miúda & $223,00 \mathrm{~b}$ & $17,68 \mathrm{~b}$ & 480,17 & $37,52 \mathrm{a}$ \\
\hline & & & & \\
\hline Genótipo (G) & $22,85 * *$ & $1,37^{\mathrm{ns}}$ & $16,98 * *$ & $5,46^{*}$ \\
\hline Densidade (D) & $1,06^{\mathrm{ns}}$ & $13,70 * *$ & $0,73^{\mathrm{ns}}$ & $10,29 * *$ \\
\hline$G \times D$ & $1,28^{\mathrm{ns}}$ & $1,55^{\mathrm{ns}}$ & $1,40^{\mathrm{ns}}$ & $1,28^{\mathrm{ns}}$ \\
\hline CV (\%) & 39,67 & 38,82 & 39,24 & 41,88 \\
\hline
\end{tabular}

Médias seguidas de mesma letra, na coluna, não diferem pelo teste Tukey, a $5 \%$. **, * e ns: significativo a $1 \%$ e $5 \%$ e não significativo, respectivamente.

Tabela 4. Teores de matéria seca (MS), matéria mineral (MM), matéria orgânica (MO), proteína bruta (PB), extrato etéreo (EE), fibra em detergente ácido (FDA), FDA corrigida para cinza e proteína (FDAcp), lignina, proteína indigestível em detergente ácido $\left(\mathrm{PIDA}_{\% \mathrm{~PB}}\right.$ ), proteína indigestível em detergente ácido da $\mathrm{MS}\left(\mathrm{PIDA}_{\% \mathrm{MS}}\right)$, fibra em detergente neutro (FDN), FDN corrigida para cinza e proteína (FDNcp), hemicelulose, celulose, proteína indigestível em detergente neutro (PIDN ${ }_{\% \mathrm{~PB}}$ ) e proteína indigestível em detergente neutro da $\mathrm{MS}\left(\mathrm{PIDN}_{\% \mathrm{MS}}\right)$ da palma forrageira, em diferentes densidades de cultivo (Frei Paulo, SE, 2011).

\begin{tabular}{|c|c|c|c|c|c|c|c|}
\hline \multirow{2}{*}{$\begin{array}{c}\text { Variável } \\
\% \text { da MS }\end{array}$} & \multicolumn{3}{|c|}{ Variedade } & \multicolumn{4}{|c|}{ Valor de F } \\
\hline & Gigante & Redonda & Miúda & Genótipo $(\mathrm{G})$ & Densidade (D) & GxD & $\mathrm{CV}(\%)$ \\
\hline $\mathrm{MS}^{1}$ & $6,37 \mathrm{~b}$ & $6,07 \mathrm{~b}$ & $7,76 \mathrm{a}$ & $15,88 * *$ & $0,62^{\mathrm{ns}}$ & $0,38^{\mathrm{ns}}$ & 11,66 \\
\hline MM & $15,94 \mathrm{~b}$ & $17,75 \mathrm{a}$ & $17,53 \mathrm{~b}$ & $7,53 * *$ & $0,29^{\mathrm{ns}}$ & $1,61^{\mathrm{ns}}$ & 7,33 \\
\hline MO & $84,07 \mathrm{a}$ & $82,25 \mathrm{~b}$ & $82,48 \mathrm{~b}$ & $7,52 * *$ & $0,29^{\text {ns }}$ & $1,61^{\mathrm{ns}}$ & 1,51 \\
\hline PB & $5,42 \mathrm{a}$ & $5,21 \mathrm{a}$ & $4,31 \mathrm{~b}$ & $9,64 * *$ & $1,22^{\text {ns }}$ & $1,14^{\mathrm{ns}}$ & 13,22 \\
\hline $\mathrm{EE}$ & 2,98 & 3,20 & 3,09 & $0,29^{\text {ns }}$ & $1,28^{\mathrm{ns}}$ & $2,25^{\mathrm{ns}}$ & 22,78 \\
\hline FDA & 20,93 & 19,32 & 19,97 & $0,60^{\mathrm{ns}}$ & $0,10^{\mathrm{ns}}$ & $1,75^{\mathrm{ns}}$ & 18,07 \\
\hline FDAcp & 18,39 & 17,34 & 18,48 & $0,39^{\text {ns }}$ & $0,11^{\mathrm{ns}}$ & $2,07^{\mathrm{ns}}$ & 19,43 \\
\hline Lignina & $5,26 \mathrm{a}$ & $5,30 \mathrm{a}$ & $3,57 \mathrm{~b}$ & $7,18 * *$ & $3,34 *$ & $4,36^{\mathrm{ns}}$ & 27,01 \\
\hline PIDA $_{\% \mathrm{~PB}}$ & 18,06 & 13,62 & 14,05 & $2,42^{\mathrm{ns}}$ & $0,37^{\mathrm{ns}}$ & $1,09^{\mathrm{ns}}$ & 35,79 \\
\hline PIDA $_{\% \mathrm{MS}}$ & 0,92 & 0,85 & 0,60 & $2,91^{\mathrm{ns}}$ & $0,96^{\mathrm{ns}}$ & $0,83^{\mathrm{ns}}$ & 43,16 \\
\hline FDN & 28,30 & 27,05 & 32,81 & $2,92^{\mathrm{ns}}$ & $1,15^{\text {ns }}$ & $0,84^{\mathrm{ns}}$ & 20,88 \\
\hline FDNcp & 22,05 & 19,18 & 24,30 & $2,24^{\mathrm{ns}}$ & $1,51^{\mathrm{ns}}$ & $0,73^{\text {ns }}$ & 27,17 \\
\hline Hemicelulose & 7,38 & 7,73 & 12,84 & $2,24^{\mathrm{ns}}$ & $0,61^{\mathrm{ns}}$ & $1,29^{\mathrm{ns}}$ & 75,90 \\
\hline Celulose & 15,67 & 14,02 & 16,40 & $1,25^{\mathrm{ns}}$ & $0,53^{\text {ns }}$ & $1,20^{\mathrm{ns}}$ & 24,60 \\
\hline $\mathrm{PIDN}_{\% \mathrm{MS}}$ & $1,61 \mathrm{a}$ & $0,53 \mathrm{~b}$ & $1,02 \mathrm{ab}$ & $4,37 *$ & $0,42^{\text {ns }}$ & $0,39^{\mathrm{ns}}$ & 85,57 \\
\hline $\mathrm{PIDN}_{\% \mathrm{~PB}}$ & $27,30 \mathrm{a}$ & $4,43 \mathrm{~b}$ & $20,62 \mathrm{a}$ & $11,14 * *$ & $0,82^{\text {ns }}$ & $0,87^{\mathrm{ns}}$ & 69,92 \\
\hline
\end{tabular}

$1 \%$ do alimento. Médias seguidas de mesma letra, na linha, não diferem pelo teste Tukey, a 5\%. **, * e ns: significativo a $1 \%$ e $5 \%$ e não significativo, respectivamente.

Os genótipos Redonda e Gigante apresentaram maiores valores de MM (17,75\%) e MO (84,07\%), respectivamente, semelhantemente ao teor detectado por Torres et al. (2009) para MO, mas inferior para MM. Esses valores podem ser justificados pelo fato de tais genótipos apresentarem cladódios maiores e mais estruturados que os da palma Miúda.

O teor médio de PB de 4,98\% (Tabela 4), para todos os tratamentos, é semelhante à média encontrada por Torres et al. (2009). No entanto, o teor médio de MS de 6,73\% difere da média de Ferreira et al. (2006) e Torres et al. (2009), de 11,69 $\pm 2,56 \%$ e $10,1 \%$, respectivamente. O menor teor médio de MS encontrado no presente trabalho deve-se, provavelmente, à avaliação de plantas mais jovens, em relação aos trabalhos citados. O menor valor de PB encontrado na palma Miúda deve-se à diluição desse nutriente pelo NCP maior desse genótipo, em relação ao Gigante e Redonda. A palma Miúda apresentou maior teor e maior produtividade de MS 
e, consequentemente, a PB desse genótipo equivale à presente nos demais genótipos, para uma mesma área de cultivo. A palma Miúda dispõe de maior quantidade de PB disponível por área, por apresentar maior produtividade.

Cada tecido possui composição física e química diretamente relacionada com sua estrutura na planta, por exemplo, tecidos de sustentação devem ser densamente agrupados, espessados e lignificados. Já um tecido especializado para realizar a fotossíntese deve possuir células com parede delgada e não-lignificada (Valente et al. 2011). Por isso, observa-se que o genótipo Gigante apresentou a maior altura de planta e comprimento de cladódio e que o Redonda, mesmo com altura menor que a do Miúda, caracteristicamente apresentou cladódios mais largos (Tabela 2). Contudo, apresentando cladódios mais desenvolvidos e bem estruturados, consequentemente, apresentam tecidos mais lignificados.

Não houve diferença significativa entre os genótipos, para o teor de proteína indigestível em detergente ácido da MS ( PIDA $\left._{\% \mathrm{MS}}\right)$, ou seja, a proteína que está indisponível por estar ligada à fração indigestível, dessa forma, não é assimilada pelo ruminante. Mesmo assim, observou-se que a palma Miúda apresentou teor de PIDA $_{\% \mathrm{MS}}$ menor que o da Redonda e Gigante, por apresentar os maiores teores de celulose e hemicelulose. Assim, mesmo apresentando menor teor de $\mathrm{PB}$, proporcionalmente, está mais disponível aos ruminantes que nas palmas Gigante e Redonda. Já os genótipos Gigante e Redonda apresentaram menores percentagens de frações solúveis em detergente neutro e maior presença de lignina compondo seus carboidratos estruturais. Consequentemente, essas frações podem complexar-se com a proteína, tornando-a indigestível.

Na Figura 4, observa-se resposta positiva e quadrática ao aumento de densidades, para a variável lignina. Com o aumento da densidade de plantio, a planta tende a diminuir a quantidade de cladódios emitidos e seus tamanhos, porém, agora a planta enfrenta menor competição de nutrientes, em termos de número de cladódios, e, assim, esses passam a ser mais estruturados.

Quando a densidade de cultivo ultrapassa 40.000 plantas ha ${ }^{-1}$, o teor de lignina diminui, pois agora os cladódios são menores. Porém, devido ao menor número de cladódios por planta, consequentemente, há maior teor de nutrientes por cladódio nessas plantas. Isso corrobora Cunha et. al. (2012), os quais afirmaram que a variação na distribuição dos nutrientes pela planta influencia nas características de desenvolvimento dos cladódios.

Os altos teores de carboidratos totais na palma forrageira (Tabela 5) estão próximos aos de concen-

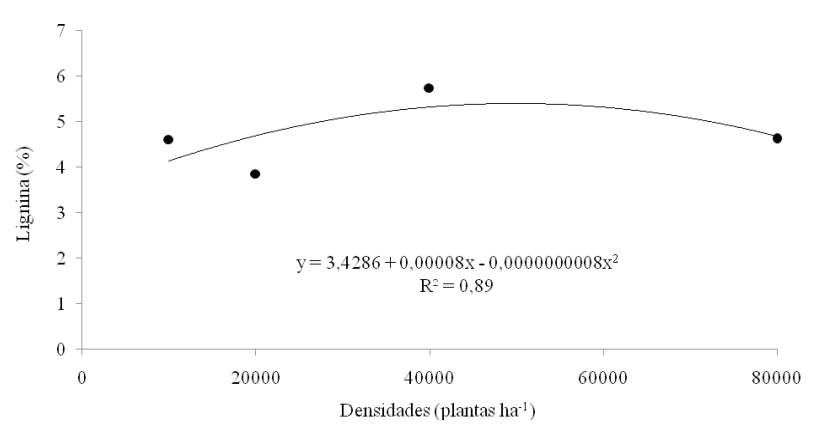

Figura 4. Teor de lignina das palmas forrageiras Gigante, Redonda e Miúda, em função da densidade de plantio (Frei Paulo, SE, 2011).

Tabela 5. Teores de carboidratos totais (CHOT), carboidratos não fibrosos (CNF), carboidratos não fibrosos corrigidos para cinza e proteína (CNFcp), nutrientes digestíveis totais $\left(\mathrm{NDT}_{\mathrm{USA}}\right.$ e $\mathrm{NDT}_{\mathrm{CAPELLE}}$ ) e digestibilidade in vitro da matéria seca (DIVMS) da palma forrageira, em função da densidade de plantio (Frei Paulo, SE, 2011).

\begin{tabular}{|c|c|c|c|c|c|c|}
\hline \multirow{2}{*}{ Tratamento } & $\mathrm{CHOT}$ & $\mathrm{CNF}$ & CNFcp & $\mathrm{NDT}_{\text {USA }}$ & $\mathrm{NDT}_{\text {CAPELLE }}$ & DIVMS \\
\hline & \multicolumn{6}{|c|}{$\%$} \\
\hline Gigante & $75,67 \mathrm{a}$ & 47,37 & 53,62 & 56,87 & 71,99 & $52,616 \mathrm{~b}$ \\
\hline Redonda & $73,84 \mathrm{~b}$ & 46,79 & 54,66 & 55,96 & 72,51 & $55,13 \mathrm{~b}$ \\
\hline \multirow[t]{2}{*}{ Miúda } & $75,08 \mathrm{ab}$ & 42,27 & 50,78 & 57,33 & 70,11 & $58,134 \mathrm{a}$ \\
\hline & \multicolumn{6}{|c|}{ Valor de F } \\
\hline Genótipo $(\mathrm{G})$ & $3,60 *$ & $2,64^{\mathrm{ns}}$ & $1,26^{\mathrm{ns}}$ & $0,63^{\mathrm{ns}}$ & $2,92^{\mathrm{ns}}$ & $6,15^{* *}$ \\
\hline Densidade (D) & $1,20^{\mathrm{ns}}$ & $0,96^{\mathrm{ns}}$ & $1,18^{\mathrm{ns}}$ & $0,96^{\mathrm{ns}}$ & $1,15^{\mathrm{ns}}$ & $0,65^{\mathrm{ns}}$ \\
\hline$G \times D$ & $2,24^{\mathrm{ns}}$ & $1,51^{\mathrm{ns}}$ & $1,17^{\mathrm{ns}}$ & $1,80^{\mathrm{ns}}$ & $0,84^{\mathrm{ns}}$ & $1,32^{\mathrm{ns}}$ \\
\hline CV (\%) & 2,28 & 13,09 & 11,68 & 5,36 & 3,58 & 6,99 \\
\hline
\end{tabular}

Médias seguidas de mesma letra, na coluna, não diferem pelo teste Tukey, a 5\%. **, * e ${ }^{\text {ns: }}$ significativo a $1 \%$ e $5 \%$ e não significativo, respectivamente. 
trados geralmente utilizados na formulação de dietas para ruminantes, como milho, farelo de soja e farelo de mandioca, dentre outros.

Wanderlley et al. (2012) encontraram valores semelhantes de carboidratos totais entre a palma e silagem de sorgo (84,13\% e 84,14\%, respectivamente). No entanto, devido ao baixo teor de FDN, o valor de CNF da palma forrageira foi bem superior $(50,05 \%)$, enquanto a silagem de sorgo apresentou $19,16 \%$. Portanto, existe a necessidade de se corrigir o défice de FDN por meio de fontes de fibra fisicamente efetiva, sendo necessária, dessa forma, a associação da palma a alimentos com alto teor de fibra efetiva.

Devido aos maiores teores de MS e teores de frações pouco e não digestíveis (como FDA e lignina) inferiores aos das palmas Gigante e Redonda (Tabela 4), a palma Miúda apresentou a maior digestibilidade in vitro da matéria seca entre as espécies avaliadas (Tabela 5). Isso porque as palmas Gigante e Redonda, ao contrário da Miúda, apresentam plantas mais estruturadas, cladódios maiores e, portanto, maiores teores de compostos menos digestíveis, como FDA, lignina e PIDA.

A lignina é um constituinte da célula vegetal de baixa ou nula digestibilidade e apresenta influência sobre a digestibilidade da MS, da fibra bruta, da celulose e hemicelulose (Wanderley et al. 2012). No entanto, altas proporções de carboidratos, principalmente não fibrosos, em geral, elevam a digestibilidade da palma forrageira. Isso porque são prontamente degradados no rúmen, desaparecendo rapidamente, $\mathrm{e}$ aumentam o aporte de energia, favorecendo o crescimento microbiano e, consequentemente, a digestão.

Os teores de nutrientes são determinados a partir da MS, portanto, uma vez que tal genótipo apre- senta maiores teores de matéria seca e produtividade de MS, consequentemente, detém os maiores teores de nutrientes digestíveis totais, por isso, a palma Miúda apresentou maiores NDTha ${ }_{\text {USA }}^{-1}$ e NDTha ${ }_{\text {CAPELLE }}^{-1}$ (Tabela 6).

A quantidade de água por hectare está diretamente relacionada com a produtividade de massa verde e apresentou resposta quadrática positiva para o aumento da densidade de plantio (Figura 5). Apesar do baixo teor de matéria seca verificado na palma forrageira, os altos valores na quantidade de água disponível por hectare é um fator interessante em regiões semiáridas, nos períodos de estiagem e falta de água, quando a palma pode servir como rica reserva desse nutriente para os amimais, via alimento.

As variáveis PB e NDT por hectare (Figura 5), respectivamente, apresentaram resposta quadrática positiva para o aumento da densidade de plantio da palma forrageira. Uma vez que a produtividade de massa seca se elevou, em decorrência do aumento da densidade de plantio, o mesmo ocorreu com a quantidade de nutrientes presentes por hectare do palmal. Portanto, mesmo não existindo diferenças significativas, em termos de composição química, entre as espécies, a quantidade de nutrientes por hectare elevou-se nas maiores populações de plantas.

Além disso, as curvas de resposta para o aumento da densidade de plantio, para nutrientes totais por hectare, segundo USA (2001) $\left(\mathrm{NDTha}^{-1}{ }_{\text {USA }}\right.$ ) e Capelle et al. (2001) (NDTha ${ }_{\text {CAPELLE }}$ ), foram semelhantes (Figura 5c). No entanto, o cálculo do primeiro requer valores de PB, EE, CNF e FDN, enquanto, segundo Capelle et al. (2001), é necessário apenas o valor da FDN, o que facilita a obtenção dos valores de NDT, em trabalhos futuros. No entanto, a curva de resposta

Tabela 6. Disponibilidade de água, proteína bruta e nutrientes digestíveis totais segundo USA (2001) e Capelle et al. (2001), acumulados em dois anos, em palma forrageira, em diferentes densidades de plantio (Frei Paulo, SE, 2011).

\begin{tabular}{|c|c|c|c|c|}
\hline \multirow{3}{*}{ Tratamento } & \multirow{2}{*}{ Disponibilidade de água } & \multirow{2}{*}{ Proteína bruta } & \multicolumn{2}{|c|}{ Nutrientes digestíveis totais } \\
\hline & & & USA & Capelle \\
\hline & \multicolumn{4}{|c|}{$\mathrm{t} \mathrm{ha}^{-1}$} \\
\hline Gigante & 355,26 & 1,31 & $13,88 \mathrm{~b}$ & $17,39 \mathrm{~b}$ \\
\hline Redonda & 369,26 & 1,26 & $12,99 \mathrm{~b}$ & $16,82 \mathrm{~b}$ \\
\hline \multirow[t]{2}{*}{ Miúda } & 442,65 & 1,66 & $21,48 \mathrm{a}$ & $24,41 \mathrm{a}$ \\
\hline & \multicolumn{4}{|c|}{ Valor de $\mathrm{F}$} \\
\hline Genótipo (G) & $1,16^{\mathrm{ns}}$ & $1,24^{\mathrm{ns}}$ & $5,54 *$ & $4,82 *$ \\
\hline Densidade (D) & $13,85 * *$ & $9,88 * *$ & $9,42 * *$ & $10,31 * *$ \\
\hline Gx D & $1,56^{\mathrm{ns}}$ & $0,88^{\mathrm{ns}}$ & $1,48^{\mathrm{ns}}$ & $1,27^{\mathrm{ns}}$ \\
\hline $\mathrm{CV}(\%)$ & 38,79 & 48,14 & 42,63 & 41,98 \\
\hline
\end{tabular}

Médias seguidas de mesma letra, na coluna, não diferem pelo teste Tukey, a 5\%. **, * e ns: significativo a $1 \%$ e $5 \%$ e não significativo, respectivamente. 

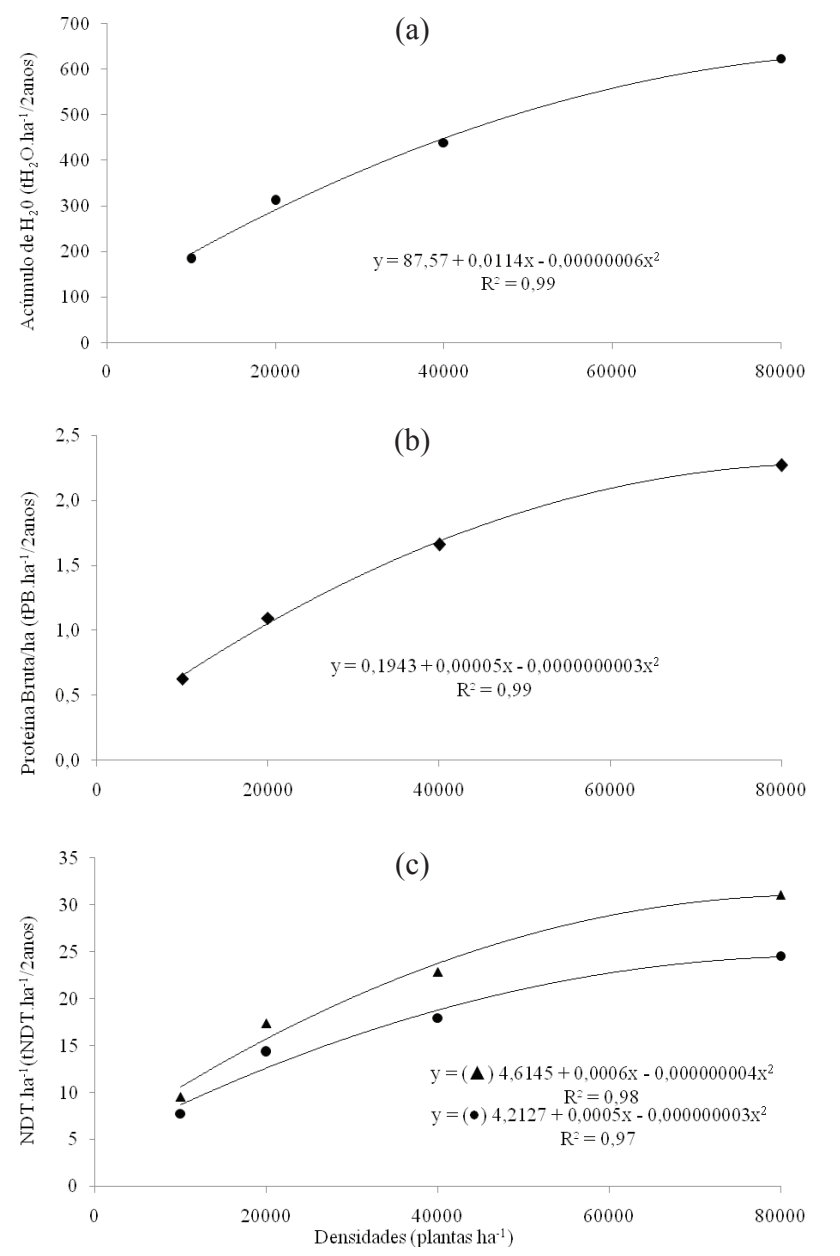

Figura 5. Acúmulo de água (a), proteína bruta (b) e nutrientes digestíveis totais (c) por hectare de palma forrageira Gigante, Redonda e Miúda, em diferentes densidades de plantio (Frei Paulo, SE, 2011).

elaborada de acordo com Capelle et al. (2001), nesse caso, forneceu valor mais elevado de NDT.

\section{CONCLUSÕES}

1. A densidade de cultivo influenciou na morfometria dos genótipos de palma forrageira avaliados, exceto para espessura de cladódio.

2. O aumento na densidade de cultivo proporcionou maior produtividade e, consequentemente, maior acúmulo de água e nutrientes por hectare/2 anos.

\section{REFERÊNCIAS}

ALVES, R. N. et al. Produção de forragem pela palma após 19 anos sob diferentes intensidades de corte e espaçamentos. Revista Caatinga, Mossoró, v. 20, n. 4, p. 38-44, 2007.

CAPELLE, E. R. et al. Estimativas do valor energético a partir de características químicas e bromatológicas dos alimentos. Revista Brasileira de Zootecnia, Brasília, DF, v. 30, n. 6, p. 1837-1856, 2001.

CAVALCANTE, N. de B.; RESENDE, G. M. de. Consumo do xiquexique (Pilocereus gounellei (A. weber ex K. Schum.) Bly. ex Rowl) por caprinos no semiárido da Bahia. Revista Caatinga, Mossoró, v. 20, n. 1, p. 22-27, 2007.

CHIACCHIO, F. P. B.; MESQUITA, A. S.; SANTOS, J. R. Palma forrageira: uma oportunidade econômica ainda desperdiçada para o semiárido baiano. Bahia Agrícola, Salvador, v. 7, n. 3, p. 39-49, 2006.

CUNHA, D. de N. F. V. da et al. Morfometria e acúmulo de biomassa em palma forrageira sob doses de nitrogênio. Revista Brasileira de Saúde e Produção Animal, Salvador, v. 13, n. 4, p. 1156-1165, 2012.

DETMANN, E.; VALADARES FILHO, S. C. On the estimation of non-fibrous carbohydrates in feeds and diets. Arquivo Brasileiro de Medicina Veterinária e Zootecnia, Viçosa, v. 62, n. 4, p. 980-984, 2010.

DUBEUX JÚNIOR, J. C. B. et al. Productivity of Opuntia ficus-indica (L.) Miller under different $\mathrm{N}$ and $\mathrm{P}$ fertilization and plant population in Northeast Brazil. Journal of Arid Enviroments, Oxford, v. 67, n. 3, p. 357-372, 2006.

DUBEUX JÚNIOR, J. C. B. et al. Adubação mineral no crescimento e composição mineral da palma forrageira Clone IPA-20. Revista Brasileira de Ciências Agrárias, Recife, v. 5, n. 1, p. 129-135, 2010.

DUBEUX JÚNIOR, J. C. B. et al. Potential of cactus pear in South America. Cactusnet Newsletter, Santiago del Estero, v. 13, ed. esp., p. 29-40, 2013.

ESPINOZA, F. H. R. et al. Rendimiento y crecimiento de nopalitos de cultivares de nopal (Opuntia ficus-indica) bajo diferentes densidades de plantación. Journal of the Professional Association for Cactus Development, Chapingo, v. 10, n. 1, p. 22-35, 2008.

FARIAS, I. et al. Manejo de colheita e espaçamento da palma-forrageira, em consórcio com sorgo granífero, no agreste de Pernambuco. Pesquisa Agropecuária Brasileira, Brasília, DF, v. 35, n. 2, p. 341-347, 2000.

FARIAS, I.; SANTOS, D. C.; DUBEUX JÚNIOR, J. C. B. Estabelecimento e manejo da palma forrageira. In: MENEZES, S. C. R.; SIMÕES, D. A.; SAMPAIO, E. V. S. B. (Eds.). A palma no Nordeste do Brasil: conhecimento atual e novas perspectivas de uso. Recife: Ed. da UFPE, 2005. p. 81-103. 
FERREIRA, C. A. et al. Utilização de técnicas multivariadas na avaliação da divergência genética entre clones de palma forrageira (Opuntia ficus-indica Mill.). Revista Brasileira de Zootecnia, Brasília, DF, v. 32, n. 6, p. 1560-1568, 2006.

HALL, M. B. Challenges with non-fiber carbohydrate methods. Journal of Animal Science, Champaign, v. 81, n. 12, p. 3226-3232, 2003.

LICITRA, G.; HERNANDEZ, T. M.; VAN SOEST, P. J. Standardization of procedures for nitrogen fractionation of ruminant feeds. Animal Feed Science and Technology, Ithaca, v. 57, n. 4, p. 347-358, 1996.

MELO, A. A. S. et al. Substituição parcial do farelo de soja por ureia e palma forrageira (Opuntia ficus indica Mill.) em dietas para vacas em lactação: I. Desempenho. Revista Brasileira Zootecnia, Brasília, DF, v. 32, n. 3, p. 727-736, 2003.

NASCIMENTO, J. P. et al. Caracterização morfométrica de Opuntia ficus-indica sob diferentes arranjos populacionais e fertilização fosfatada. Tecnologia \& Ciência Agropecuária, João Pessoa, v. 5, n. 3, p. 21-26, 2011.

OLIVEIRA JÚNIOR, S. et al. Crescimento vegetativo da palma forrageira (Opuntia ficus-indica) em função do espaçamento no semiárido paraibano. Tecnologia \& Ciência Agropecuária, João Pessoa, v. 3, n. 1, p. 7-12, 2009.

RAMOS, J. P. de F. et al. Crescimento vegetativo de Opuntia ficus-indica em diferentes espaçamentos de plantio. Revista Caatinga, Mossoró, v. 24, n. 3, p. 41-48, 2011.

ROMO, M. M. et al. Digestibilidad in situ de dietas con harina de nopal deshidratado conteniendo un preparado de enzimas fibrolíticas exógenas. Pesquisa Agropecuária Brasileira, Brasília, DF, v. 41, n. 7, p. 1173-1177, 2006.

SANTOS, M. V.F. et al. Efeito do período de armazenamento pós-colheita sobre o teor de matéria seca e composição química das palmas forrageiras. Pesquisa Agropecuária Brasileira, Brasília, DF, v. 27, n. 6, p. 777-783, 1992.

SANTOS, M. V. F. et al. Estudo comparativo das cultivares de palma forrageira Gigante, Redonda (Opuntia ficus indica Mill.) e Miúda (Nopalea cochenillifera Salm-Dyck.) na produção de leite. Revista da Sociedade Brasileira de Zootecnia, Viçosa, v. 19, n. 6, p. 504-511, 1990.

SAS INSTITUTE. SAS user's guide: statistics. Version 9.1. Cary: SAS Institute, 2002.

SILVA, D. J.; QUEIROZ, A. C. de. Análise de alimentos: métodos químicos e biológicos. 3. ed. Viçosa: UFV, 2002.

SILVA, J. A. da et al. Composição mineral em cladódios de palma forrageira sob diferentes espaçamentos e adubações químicas. Revista Brasileira de Ciências Agrárias, Recife, v. 7, supl., p. 866-875, 2012.

SNIFFEN, C. J. et al. A net carbohydrate and protein system for evaluating cattle diets: II. Carbohydrate and protein availability. Journal of Animal Science, Champaign, v. 70, n. 11, p. 3562-3577, 1992.

SOBRAL, L. F. et al. Recomendações para o uso de corretivos e fertilizantes no Estado de Sergipe. Aracaju: Embrapa Tabuleiros Costeiros, 2007.

TILLEY, J. M. A.; TERRY, R. A. A two-stage technique for the in vitro digestion of forage crop. Journal of the British Grassland Society, Oxford, v. 18, n. 2, p. 104-111, 1963.

TORRES, L. C. L. et al. Substituição da palma-gigante por palma-miúda em dietas para bovinos em crescimento e avaliação de indicadores internos. Revista Brasileira de Zootecnia, Brasília, DF, v. 38, n. 11, p. 2264-2269, 2009.

TOSTO, M. S. L. et al. Composição química e estimativa de energia da palma forrageira e do resíduo desidratado de vitivinícolas. Revista Brasileira de Saúde e Produção Animal, Salvador, v. 8, n. 3, p. 239-249, 2007.

USA. National Research Council. Nutrient requirements of dairy cattle. 7. rev. ed. Washington, D. C.: National Academy Press, 2001.

VALENTE, T. N. P. et al. Anatomia de plantas forrageiras e a disponibilidade de nutrientes para ruminantes. Veterinária e Zootecnia, Botucatu, v. 18, n. 3, p. 347-358, 2011.

VAN SOEST, P. J.; ROBERTSON, J. B.; LEWIS, B. A. Methods for dietary fiber, neutral detergent fiber, and nonstarch polysaccharides in relation to animal nutrition. Journal of Dairy Science, Champaign, v. 74, n. 10, p. 35833597, 1991.

VASCONCELOS, A. G. V. et al. Micropropagação de palma forrageira cv. Miúda (Nopalea cochenillifera Salm Dyck). Revista Brasileira de Ciências Agrárias, Recife, v. 2, n. 1, p. 28-31, 2007.

WANDERLEY, W. L. et al. Consumo, digestibilidade e parâmetros ruminais em ovinos recebendo silagens e fenos em associação à palma forrageira. Revista Brasileira de Saúde e Produção Animal, Salvador, v. 13, n. 2, p. 444456, 2012. 